\title{
Radiographic Rate and Clinical Impact of Pseudarthrosis in Spine Radiosurgery for Metastatic Spinal Disease
}

Michael Zhang ${ }^{1}$, Geoff Appelboom ${ }^{1}$, John K. Ratliff ${ }^{1}$, Scott G. Soltys ${ }^{2}$, John R. Adler Jr. ${ }^{3}$, Jon Park ${ }^{4}$, Steven D. Chang ${ }^{1}$

1. Department of Neurosurgery, Stanford University School of Medicine, Stanford, USA 2. Department of Radiation Oncology, Stanford University School of Medicine, Stanford, USA 3. Department of Radiation Oncology, Stanford University Medical Center, Stanford, CA, USA 4. Department of Neurosurgery, Stanford University Medical Center, Stanford, USA

Corresponding author: Michael Zhang, mzhang511@gmail.com

\section{Abstract \\ Purpose}

Pseudarthrosis within the spine tumor population is increased from perioperative radiation and complex stabilization for invasive and recurrent pathology. We report the radiographic and clinical rates of pseudarthrosis following multiple courses of instrumented fusion and perioperative stereotactic radiosurgery (SRS).

\section{Methods}

We performed a single institution review of 418 patients treated with non-isocentric SRS for spine between October 2002 and January 2013, identifying those with spinal instrumentation and greater than six months of follow-up. Surgical history, radiation planning, and radiographic outcomes were documented.

\section{Results}

Eleven patients who met criteria for inclusion underwent 21 sessions of spinal SRS and 16 instrumented operations. Radiographic follow-up was 48.9 months; 3/11 (27\%) were with radiographic hardware failure, and one (9\%) separate case ultimately warranted externalization due to tumor recurrence. SRS was administered to treat progression of disease in 12/21 (57\%) procedures, and residual lesions in 7/11 (64\%) procedures. Following first and second SRS, 8/11 (73\%) and 2/7 (29\%) patients were with symptomatic improvement, respectively.

\section{Conclusion}

Received 10/21/2018 Review began 10/25/2018 Review ended 11/14/2018 Published 11/25/2018

๑) Copyright 2018 Zhang et al. This is an open access article distributed under the terms of the Creative Commons Attribution License CC-BY 3.0., which permits unrestricted use, distribution, and reproduction in any medium, provided the original author and source are credited.
Risk of pseudarthrosis following SRS for patients with oncologic spinal lesions will become increasingly apparent with the optimized management of and survival from spinal pathologies. We highlight how the need for local control outpaces the risk of instrumentation failure.

Categories: Radiation Oncology, Neurosurgery

Keywords: pseudarthrosis, hardware failure, stereotactic radiosurgery, spinal column metastases

\section{Introduction}

The management of spinal column metastasis has increasingly moved towards less invasive separation surgery followed by adjuvant stereotactic radiosurgery (SRS). This decompressive approach reduces the post-operative recovery burden while preserving high levels of functional independence $[1,2]$. However, aggressive surgical stabilization and construct extension is still warranted among destabilizing and multiply-recurrent pathologies for preservation of function. The advantages and disadvantages of these large spinal constructs in already poor quality bone subject to further irradiation, become important in the pre-operative discussion.

Despite its radiobiological stressors, SRS is with known benefits toward pain and disease control [3-5]. The movement from adjuvant external radiation therapy (XRT) to SRS for spinal column metastasis provides higher doses with steeper drop-offs limiting direct radiation to the bony matrix and spinal cord $[1,6,7]$. Nevertheless, the long oncologic course for these patients exposes them to multiple treatment sessions and multiple modalities of radiation that additively undermine desirable fusion. Concerns for decreased periosteal osteoblastic proliferation, decreased vascularity, and increased bony pliancy subject patients to the risks of hardware failure, including implant migration, fusion failure, and biomechanical destabilizationassociated pain that can warrant surgical revision $[8,9]$.

Unfortunately, the reduced life expectancies and post-operative tolerances of the overall spinal tumor population has made an assessment of post-SRS pseudarthrosis difficult. Furthermore, published series are limited by their partial reporting of radiation treatment history or follow-up, leading to a wide range of pseudarthrosis rates that are difficult to compare. Thus, the collective impact of serial, surgical and adjuvant radiation treatments on surgical decision-making is absent. Therefore, we assessed patients with perioperative SRS for recurrent spinal column metastasis necessitating instrumentation to qualify how the 


\section{Materials And Methods \\ Patient population}

A retrospective review of a prospectively collected database of patients treated with non-isocentric SRS between October 2002 and May 2013 was performed. We limited assessment to patients with instrumented fusion with post-surgical SRS radiation, and at least six months of radiographic follow-up. From a total of 418 patients who were treated with SRS, 42 (10\%) were with prior surgery and instrumentation, 35 (8.4\%) with Karnofsky performance score (KPS) > 70, and 11 (2.6\%) patients who met criteria for inclusion.

Primary outcome measured for the rate hardware failure, including radiographic and clinical pseudarthrosis, as well as the rate of operative externalization. Demographic and risk factors including sex, age at treatment, weight, smoking history, osteoporosis, primary disease histology, and KPS at time of index SRS treatment were recorded. All aspects of the study were performed in accordance with relevant guidelines and regulations as were approved by the Stanford Institute Review Board. Written informed consent was not required given the retrospective study format.

\section{Treatment}

Surgical and SRS treatment history were characterized for analysis. All instrumented and non-instrumented fusions to the spine were documented. Individual surgical interventions were further assessed for indication, need for instrumentation, time from any preceding SRS or instrumented surgery, location relative to prior surgery, symptoms prior to treatment, response to treatment, surgical approach as well as incorporation of corpectomy, junctional levels, and graft.

Regarding radiation treatment, all sessions with exposure to the spine by either conventional radiation therapy or SRS were documented. Individual SRS interventions, which were all performed at the authors' institution, were further assessed for indication, levels treated, time from index instrumented-surgery, time from prior SRS, location relative to prior SRS, symptoms prior to SRS, and response to treatment. Biological equivalent doses were estimated with an alpha/beta of 10 .

\section{Statistical analyses}

Differences in means and proportions were determined by Mann-Whitney/un-paired t-test. Probabilistic univariate and multivariate analyses were performed by logistic regressions. Statistical analyses were performed using Stata/SE 13.1 Software (StataCorp, College Station, TX, USA). Statistical significance was targeted for $\mathrm{p}<0.05$.

\section{Results}

For the 11 patients who met inclusion criteria, mean radiographic follow-up was 48.9 (6-121) months. Assessment of primary outcomes identified four (36\%) patients with hardware failure, within which 3/11 (27\%) were with radiographically confirmed pseudarthrosis (Table 1). Among these patients, externalization was performed in one (9\%) patient for screw loosening, which ultimately was attributed to tumor involvement. Clinically attributed neck pain was reported in $1 / 11(9 \%)$, but no pseudarthrosis was detected and no revision was performed. Individual risk factors included 1/11 (9\%) patients with osteoporosis, 4/11 (36\%) with former smokers (none current), and 7/11 (64\%) with elevated body mass index (BMI). All patients underwent chemotherapy after SRS, but 5/11 (45\%) had not initiated a regimen beforehand. Two (18\%) patients were with protracted steroid treatment. Three (27\%) patients had unfavorable histologies, including one with lung and two with prostate primaries. The remaining patients were treated for breast, melanoma, thyroid, thymoma, and multiple myeloma [7].

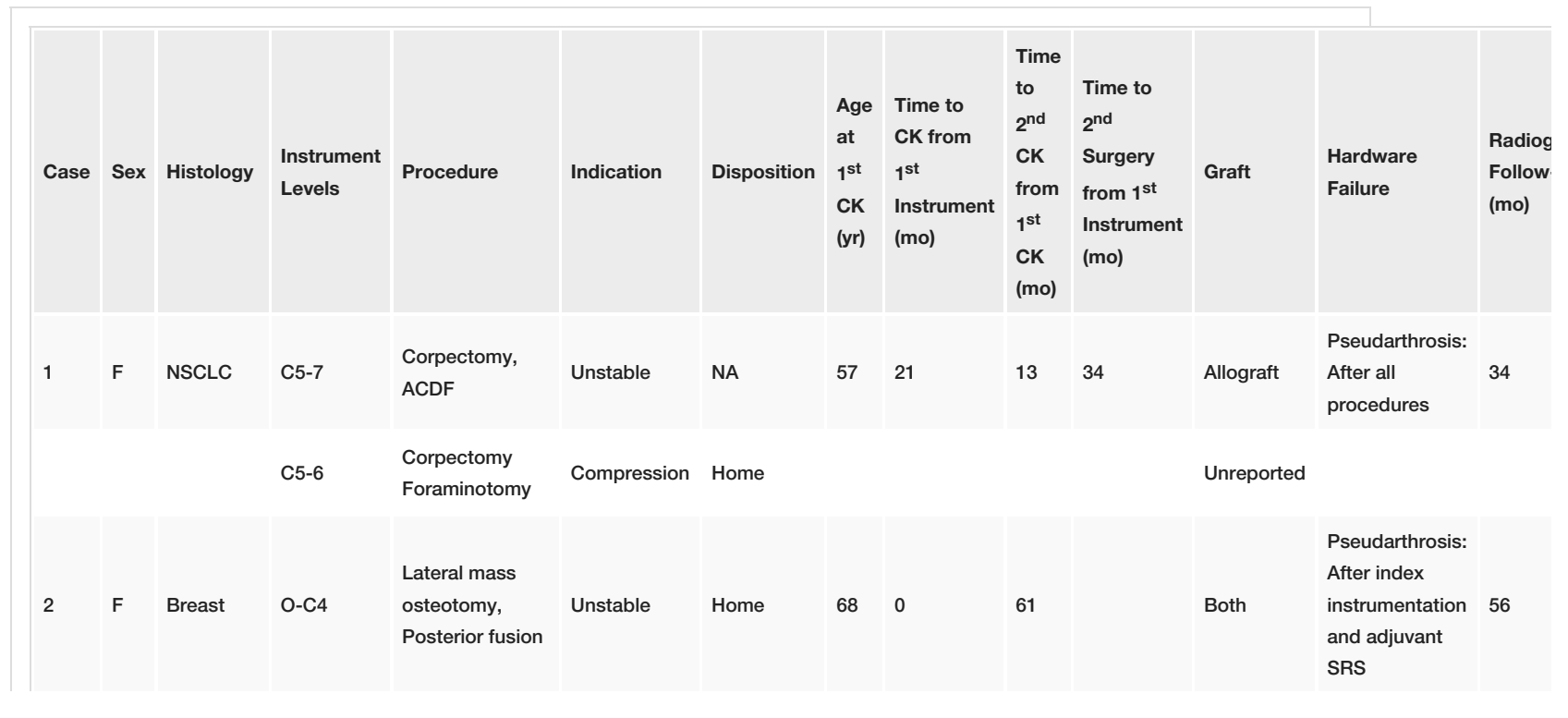




\begin{tabular}{|c|c|c|c|c|c|c|c|c|c|c|c|c|c|}
\hline 3 & $\mathrm{~F}$ & Breast & C1-4 & Posterior fusion & Unstable & Home & 58 & 2 & & & Allograft & $\mathrm{N}$ & 56 \\
\hline \multirow[t]{2}{*}{4} & M & RCC & L2-4 & $\begin{array}{l}\text { Corpectomy, } \\
\text { Posterior fusion }\end{array}$ & Unstable & Home & 59 & 6 & 5 & 18 & Both & $\begin{array}{l}\text { Externalized: At } \\
\text { second } \\
\text { instrumentation }\end{array}$ & 30 \\
\hline & & & T10-S1 & $\begin{array}{l}\text { Posterior fusion, } \\
\text { Removal of prior } \\
\text { instrumentation }\end{array}$ & Compression & Home & & & & & Autograft & & \\
\hline 5 & M & RCC & $\begin{array}{l}\text { T10-12 T8- } \\
\text { L2 }\end{array}$ & $\begin{array}{l}\text { Corpectomy, } \\
\text { Anterior and } \\
\text { Poster Fusion, }\end{array}$ & Unstable & Rehab. & 66 & 0 & 10 & & Allograft & $\mathrm{N}$ & 34 \\
\hline \multirow[t]{4}{*}{6} & M & Melanoma & NA & [Laminectomy] & NA & NA & 56 & 3 & 7 & 11 & NA & $\mathrm{N}$ & 19 \\
\hline & & & C7-T9 & Posterior fusion & Compression & Home & & & & & Unreported & & \\
\hline & & & C5-T8 & Posterior fusion & Compression & Home & & & & & Allograft & & \\
\hline & & & T3-T5 & $\begin{array}{l}\text { Corpectomy, } \\
\text { Posterior fusion }\end{array}$ & Compression & Home & & & & & Allograft & & \\
\hline \multirow[t]{4}{*}{7} & M & Melanoma & NA & $\begin{array}{l}\text { [Aborted } \\
\text { resection] }\end{array}$ & NA & NA & 49 & 1 & 14 & 9 & NA & $\mathrm{N}$ & 21 \\
\hline & & & T2-T7 & Posterior fusion & Compression & Home & & & & & Both & & \\
\hline & & & T3-T7 & $\begin{array}{l}\text { Corpectomy, } \\
\text { Anterior and } \\
\text { Posterior fusion }\end{array}$ & Compression & Home & & & & & Both & & \\
\hline & & & NA & [Laminectomy] & NA & Rehab. & & & & & & & \\
\hline \multirow[t]{3}{*}{8} & M & Melanoma & NA & $\begin{array}{l}\text { [Uninstrumented } \\
\text { resection] }\end{array}$ & NA & NA & 74 & 6 & 4 & & NA & $\mathrm{N}$ & 62 \\
\hline & & & NA & $\begin{array}{l}\text { [Uninstrumented } \\
\text { resection] }\end{array}$ & NA & NA & & & & & NA & & \\
\hline & & & C7-T2 & Posterior fusion & Compression & Home & & & & & Both & & \\
\hline 9 & $\mathrm{~F}$ & Thyroid & T4-T8 & $\begin{array}{l}\text { Corpectomy, } \\
\text { Posterior fusion }\end{array}$ & Unstable & Home & 64 & 16 & 44 & & Allograft & $\begin{array}{l}\text { Pseudarthrosis: } \\
\text { After all } \\
\text { procedures }\end{array}$ & 121 \\
\hline \multirow[t]{2}{*}{10} & M & Thymoma & T6-T10 & $\begin{array}{l}\text { Corpectomy, } \\
\text { Posterior fusion }\end{array}$ & Compression & Home & 41 & 1 & & & Allograft & $\mathrm{N}$ & 6 \\
\hline & & & NA & [Laminectomy] & NA & NA & & & & & NA & & \\
\hline 11 & M & $\begin{array}{l}\text { Muitiple } \\
\text { Myeloma }\end{array}$ & T4-T8 & Posterior fusion & Compression & Home & 34 & 38 & 61 & & Allograft & $\mathrm{N}$ & 99 \\
\hline
\end{tabular}

TABLE 1: Surgical instrumentation, peri-operative timeline, and fusion features.

CK: CyberKnife; F: Female; Gy: Gray; M: Male; NA: Not applicable; NSCLC: Non-small cell lung cancer; mo: month; RCC: Renal cell carcinoma; yr: year.

There were a total of 21 sessions of non-isocentric hypofractionated treatment of spinal SRS, all treated by CyberKnife at the authors' institution, and 12 sessions of spinal RT (Table 2). After index SRS, nine (82\%) patients underwent repeat SRS and one (9\%) patient required a third session. Time to SRS after first instrumented surgery was median three (0-38) months. A mean $1.0(1-3)$ and $2.5(1-3)$ levels were treated at first and second SRS, respectively. Median time to second SRS was 13.0 months (4-61). Among the eight repeat treatment plans, one took place at a distinctly separate spinal distribution. SRS treatment plans were with median 24 Gy (16-35) prescription dose, in median three fractions (1-5) to the $80 \%(70-84)$ isodose line with a median maximum dose of $29.3 \mathrm{~Gy}(20.5-43.8)$. A median $23.5 \mathrm{cc}(0.77-247)$ was treated with a median conformity index of 1.35 (1.1-2.04). Notably, the biological equivalent dose (BED) for those without instrumentation failure was higher, with median BED for those with and without failure at 51.3 (40-70.4) Gy vs $42.4(35.7-50.4) \mathrm{Gy}(\mathrm{p}=0.0051)$, respectively. 


\begin{tabular}{|c|c|c|c|c|c|c|c|c|c|}
\hline Case & $\begin{array}{l}\text { CK } \\
\text { Session }\end{array}$ & Indication & $\begin{array}{l}\text { SRS } \\
\text { Target }\end{array}$ & $\begin{array}{l}\text { Prescription } \\
\text { Dose (Gy) }\end{array}$ & Fractions & $\begin{array}{l}\text { Max } \\
\text { Dose } \\
\text { (Gy) }\end{array}$ & $\begin{array}{l}\text { Volume } \\
\text { (cc) }\end{array}$ & Cl & Other Radiation Treatment \\
\hline \multirow[t]{3}{*}{1} & 1st & Progression & C1-2 & 24 & 3 & 29.27 & 17.13 & 1.61 & Once, after index instrumentation \\
\hline & 1st & & C5-6 & 24 & 3 & 29.63 & 17.79 & 1.68 & \\
\hline & 2nd & Residual & C6 & 20 & 2 & 26.32 & 12.35 & 1.28 & \\
\hline \multirow[t]{2}{*}{2} & 1st & Residual & $\mathrm{C} 2$ & 25 & 5 & 31.25 & 30.83 & 1.48 & NA \\
\hline & 2nd & Progression & C1-3 & 27 & 3 & 33.75 & 60.80 & 1.10 & \\
\hline 3 & 1st & $\begin{array}{l}\text { Primary } \\
\text { Control }\end{array}$ & C2 & 24 & 3 & 30 & 13.76 & 1.29 & $\begin{array}{l}\text { Twice, after index } \\
\text { instrumentation/adjuvant SRS }\end{array}$ \\
\hline \multirow[t]{4}{*}{4} & 1st & Progression & T12 & 21 & 3 & 25.82 & 6.20 & 1.63 & Once, prior to index instrumentation \\
\hline & 1st & & L1 & 21 & 3 & 26.25 & 26.20 & 1.73 & NA \\
\hline & 1st & & L2 & 21 & 3 & 26.04 & 23.50 & 1.52 & \\
\hline & 2nd & Progression & L3 & 24 & 3 & 32 & 8.46 & 1.27 & \\
\hline \multirow[t]{3}{*}{5} & 1st & Residual & T11 & 22 & 1 & 28.2 & 100.67 & 1.23 & NA \\
\hline & 2nd & Progression & L1 & 20 & 1 & 25 & 42.69 & 1.22 & \\
\hline & 2nd & & L4 & 20 & 1 & 25 & 46.14 & 1.16 & \\
\hline \multirow[t]{2}{*}{6} & 1st & Boost & T4 & 16 & 1 & 20.51 & 5.11 & 1.54 & Once, before index instrumentation \\
\hline & 2nd & Residual & T4 & 20 & 2 & 23.80 & 12.56 & 1.28 & \\
\hline \multirow[t]{2}{*}{7} & 1st & Residual & T5 & 27 & 3 & 36.48 & 33.48 & 1.48 & Once, before index instrumentation \\
\hline & 2nd & Residual & T5 & 35 & 5 & 43.75 & 74.08 & 1.12 & \\
\hline \multirow[t]{2}{*}{8} & 1st & Progression & L3-4 & 20 & 2 & 25.64 & 0.85 & 2.04 & $\begin{array}{l}\text { Twice, after first and second } \\
\text { instrumentation }\end{array}$ \\
\hline & 2nd & Progression & C1-2 & 24 & 3 & 30 & 0.77 & 1.59 & \\
\hline \multirow[t]{3}{*}{9} & 1st & Progression & T6 & 27 & 4 & 35.06 & 21.04 & 1.35 & IMRT, after $3^{\text {rd }}$ CK \\
\hline & 2nd & Progression & T4-6 & 18 & 1 & 24 & 34.08 & 1.35 & \\
\hline & $3 r d$ & Progression & 13 & 18 & 1 & 23.68 & 6.28 & 1.26 & \\
\hline 10 & $1 \mathrm{st}$ & Residual & 18 & 27 & 3 & 38.57 & 30.75 & 1.86 & Once, after second Instrumentation \\
\hline \multirow[t]{2}{*}{11} & 1st & Progression & T4 & 27 & 3 & 34.61 & 35.77 & 1.20 & adjuvant and after $1^{\text {st }} \mathrm{CK}$ \\
\hline & 2nd & Progression & T9-11 & 24 & 3 & 30 & 247 & 1.29 & \\
\hline
\end{tabular}

TABLE 2: Radiation planning and radiation history.

cc: Cubic centimeter; CI: Conformity index; CK: CyberKnife; Gy: Gray; IMRT: Intensity-modulated radiation therapy; NA: Not applicable; mo: month; yr: year.

Reason for SRS at the index treatment was for residual tumor in 4/11 (36\%) patients and for tumor progression in 5/11 (45\%) patients. An additional one (9\%) patient underwent SRS initially for primary control, and one (9\%) for boost treatment. Second SRS was indicated for residual tumor and progression in $3 / 9$ (33\%) and 6/9 (67\%) patients, respectively. Among those requiring repeat SRS treatment, 1/8 (12.5\%) underwent SRS at a distinctly different spinal segment. There were 10/11 (91\%) and 7/9 (78\%) patients with symptoms at first and second SRS, and 8/11 (73\%) and 2/7 (29\%) with subsequent improvement. Two patients were without follow-up after their second SRS treatment.

A total of 16 decompressive procedures were performed. An unstable spine was identified in 6/11 (55\%) at initial presentation, and all repeat surgeries (6/6) were for decompression. Time to second surgery was median 14.5 (9-34) months. A mean 5.4 (2-10) and 3.75 (2-5) levels were treated on first and second surgery, respectively. Among the four patients who had a repeat procedure involving instrumentation, one took place at a distant spinal segment. Symptomatic improvement was experienced by $9 / 11(82 \%)$ and $1 / 4(25 \%)$ patients following their initial and second instrumented surgeries, respectively. Among index procedures, 5/11 (45\%) patients underwent a corpectomy and 4/11 (36\%) took place at a junctional level. Allograft-alone 
was utilized in 6/11 (54\%) index procedures, as well as in $1 / 4$ (25\%) and $1 / 1$ of second and third procedures, respectively. At the time of discharge, 14/16 (87.5\%) dispositions were to home.

\section{Discussion}

Current improvements in oncologic care will yield prolonged survival that demands recurrent considerations for instrumented stabilization and risks of revision [10]. Here we characterized the heterogeneous and complex clinical histories of patients with extended follow-up and determine that pseudarthrosis remains a prominent risk, as $27 \%$ were with radiographic evidence of lucency. However, a complete survey of their clinical courses suggests that patients with spinal metastasis tolerate aggressive surgical management with perioperative SRS, and may present with progression and urgent decompression needs that outpace competing hardware risks.

Variations in surgical approaches, radiographic follow-up and timing of adjunct radiation treatment make comparisons difficult between published studies, but our pseudarthrosis rate is consistent with the reported $0-43 \%$. On the lower range, Harel et al. identified no instrumentation failure $(0 / 8)$ with a more conservative median 14.75 Gy single fraction treatment at median 15.9 months, while Amankulor et al. reported a $2.8 \%$ (9/318) symptomatic hardware failure rate at a median 19 months, all with compression fractures perhaps related to long and/or posterior-only stabilization [11,12]. Aside from our broader criteria, a higher pseudarthrosis rate in our series may be attributed to longer follow-up and inclusion of patients' multiple courses of radiation, thereby capturing the lifelong pseudarthrosis rate.

Higher instrumentation failure rates were reported in earlier XRT studies where perhaps dosing regimens had not yet been optimized $[8,11]$. Emery et al. noted that patients with pseudarthrosis were all with total XRT > 40 Gy, but the statistical significance of this threshold was eliminated once converted to BED [8]. The more contemporary option for SRS with higher prescription doses is largely preferable to XRT to achieve local control $[1,7,11]$. This could preserve bony integrity and preclude implant externalization, as was necessary in one of our patients and which our BED analysis supports, perhaps obviating stress-imposing extension of constructs as in one of our cases [11].

Most importantly, our review further qualifies the role of perioperative SRS despite hardware risks [13, 14]. We see that radiographic pseudarthrosis is more prominent than symptomatic failure. Time to pseudarthrosis occurred at 36, 54, and 117 months, which was longer than the median time to retreatment. The benefits to quality of life are evident in the rate of symptomatic improvements and the rate at which they discharge to home. In the same vein, Laufer et al. reported an optimistic functional status following repeat posterolateral decompression (without radiation), with $65 \%$ still ambulatory at the time of last followup and with unchanged rates of estimated survival [6].

Our results and prior work will help counsel patients with recurring pathology and spinal surgeries. Local recurrence is estimated to affect a quarter of patients $[6,14,15]$. Likewise, re-operation is anticipated for $25 \%$ of spinal metastasis patients. Although pseudarthrosis currently does not appear to fully correlate with symptomatic failure, there is the future risk that with prolonged survival, patients will increasingly experience pain associated with instrumentation and perioperative SRS. Post-operative radiation is known to have detrimental effects on fusion, particularly in the early post-operative period $[16,17]$. If patients are anticipated to experience multiple procedures, such as those with favorable pathologies, perhaps more frequent spinal imaging should be obtained in select populations to provide neoadjuvant SRS.

\section{Conclusions}

Here we provide a complete longitudinal assessment of patients with instrumented metastatic spinal disease who required re-operation and re-irradiation, not captured in prior works. We suspect symptomatic pseudarthrosis rate is an overestimate of the problem given the number of patients lost to follow-up due to survival. We anticipate with the improvement of individualized therapy and increased availability for SRS treatment, future studies will offer greater follow-up and sample size for statistical assessment. While we reaffirm a genuine risk for pseudarthrosis following perioperative SRS, the associated symptoms are minimal and should not deter aggressive radiation and surgical management if with good prognosis.

\section{Additional Information}

\section{Disclosures}

Human subjects: All authors have confirmed that this study did not involve human participants or tissue. Animal subjects: All authors have confirmed that this study did not involve animal subjects or tissue. Conflicts of interest: In compliance with the ICMJE uniform disclosure form, all authors declare the following: Payment/services info: All authors have declared that no financial support was received from any organization for the submitted work. Financial relationships: All authors have declared that they have no financial relationships at present or within the previous three years with any organizations that might have an interest in the submitted work. Other relationships: All authors have declared that there are no other relationships or activities that could appear to have influenced the submitted work.

\section{References}

1. Moulding HD, Elder JB, Lis E, Lovelock DM, Zhang Z, Yamada Y, Bilsky MH: Local disease control after decompressive surgery and adjuvant high-dose single-fraction radiosurgery for spine metastases. J Neurosurg Spine. 2010, 13:87-93. 10.3171/2010.3.SPINE09639

2. Patchell RA, Tibbs PA, Regine WF, et al.: Direct decompressive surgical resection in the treatment of spinal cord compression caused by metastatic cancer: a randomised trial. Lancet. 2005, 366:643-648. 


\section{Cureus}

10.1016/S0140-6736(05)66954-1

3. Rock JP, Ryu S, Shukairy MS, et al.: Postoperative radiosurgery for malignant spinal tumors . Neurosurgery. 2006, 58:891-898. 10.1227/01.NEU.0000209913.72761.4F

4. Ryu S, Fang Yin F, Rock J, et al.: Image-guided and intensity-modulated radiosurgery for patients with spinal metastasis. Cancer. 2003, 97:2013-2018. 10.1002/cncr.11296

5. Ryu S, Rock J, Rosenblum M, Kim JH: Patterns of failure after single-dose radiosurgery for spinal metastasis . J Neurosurg. 2004, 101:402-405. 10.3171/ins.2004.101.supplement 3.0402

6. Laufer I, Hanover A, Lis E, Yamada Y, Bilsky M: Repeat decompression surgery for recurrent spinal metastases. J Neurosurg Spine. 2010, 13:109-115. 10.3171/2010.3.SPINE08670

7. Yamada Y, Katsoulakis E, Laufer I, et al.: The impact of histology and delivered dose on local control of spinal metastases treated with stereotactic radiosurgery. Neurosurg Focus. 2017, 42:6. 10.3171/2016.9.FOCUS16369

8. Emery SE, Hughes SS, Junglas WA, Herrington SJ, Pathria MN: The fate of anterior vertebral bone grafts in patients irradiated for neoplasm. Clinical Orthop Relat Res. 1994, 207-212.

9. Sugimoto M, Takahashi S, Toguchida J, Kotoura Y, Shibamoto Y, Yamamuro T: Changes in bone after high dose irradiation. Biomechanics and histomorphology. J Bone Joint Surg Br. 1991, 73:492-497.

10. Nater A, Sahgal A, Fehlings M: Management - spinal metastases. Handb Clin Neurol. 2018, 149:239-255 10.1016/B978-0-12-811161-1.00016-5

11. Amankulor NM, Xu R, Iorgulescu JB, et al.: The incidence and patterns of hardware failure after separation surgery in patients with spinal metastatic tumors. Spine J. 2014, 14:1850-1859. 10.1016/.j.spinee.2013.10.028

12. Harel R, Chao S, Krishnaney A, Emch T, Benzel EC, Angelov L: Spine instrumentation failure after spine tumor resection and radiation: comparing conventional radiotherapy with stereotactic radiosurgery outcomes. World Neurosurg. 2010, 74:517-522. 10.1016/j.wneu.2010.06.037

13. Bate BG, Khan NR, Kimball BY, Gabrick K, Weaver J: Stereotactic radiosurgery for spinal metastases with or without separation surgery. J Neurosurg Spine. 2015, 22:409-415. 10.3171/2014.10.SPINE14252

14. Miller JA, Balagamwala EH, Berriochoa CA, et al.: The impact of decompression with instrumentation on local failure following spine stereotactic radiosurgery. J Neurosurg Spine. 2017, 27:436-443. 10.3171/2017.3.SPINE161015

15. Weigel B, Maghsudi M, Neumann C, Kretschmer R, Muller FJ, Nerlich M: Surgical management of symptomatic spinal metastases. Postoperative outcome and quality of life. Spine. 1999, 24:2240-2246. 10.1097/00007632-199911010-00012

16. Bouchard JA, Koka A, Bensusan JS, Stevenson S, Emery SE: Effects of irradiation on posterior spinal fusions. A rabbit model. Spine. 1994, 19:1836-1841.

17. Emery SE, Brazinski MS, Koka A, Bensusan JS, Stevenson S: The biological and biomechanical effects of irradiation on anterior spinal bone grafts in a canine model. J Bone Joint Surg Am. 1994, 76:540-548. 